\title{
Towards a Viable Response to COVID-19 from the Science Education Community
}

\author{
JUSTIN DILLON ${ }^{*}$ AND LUCY AVRAAMIDOU ${ }^{¥}$
}

${ }^{*}$ Centre for Research in STEM Education, University of Exeter, St Luke’s Campus, Exeter, EX1 2LU, UK; j.s.dillon@exeter.ac.uk

${ }^{\ddagger}$ Science Education and Communication - Faculty of Science and Engineering, 9747 AG Groningen, The Netherlands; 1.avraamidou@rug.nl

\section{Responses}

JASTE is a non-refereed, open-access, journal. We encourage reader feedback on contributions to it. Please send your comments, suggestions, etc. about this paper to either Justin Dillon or Lucy Avraamidou. Thanks!

\begin{abstract}
The COVID-19 pandemic has touched almost every corner of the planet and continues to impact on lives, livelihoods, economies and cultures. It is both a human and a global phenomenon. Making sense of what is happening requires an understanding of a number of scientific ideas including viruses, transmission, incubation and vaccination. These are life and death issues and yet the public and their political leaders often display a deliberate mistrust of the science and scientists. How might the science education community respond? We pose a series of questions designed to provoke a strong response to COVID-19 from our community and our colleagues: "How well has the science curriculum prepared the world's public for COVID-19?”; “How much science education should be online from now on?”; “Are we learning from the current situation?"; "Is science education research producing knowledge that protects society from catastrophic events?"; "How should our working practices change to make science education more resilient, more useful and more transparent?"; "What are the ethics and politics of social distancing and how do they affect science education?"; "What pedagogies might we need to turn to in the future?"; and, "What role should business and industry play in funding science education research and development?" In our attempt to stimulate the development of a vision for science education in the postpandemic era, we offer initial thoughts about moving forward. What we offer is a departure point, an invitation for the community to engage with pressing issues in science education. The main question we pose is the following: What can be done, and what can be done differently? We envision that this paper will provide some guidance to the readers to re-think the complex systems and socio-political contexts within which people come to learn and practice science and to conceptualize these processes through a social justice lens. We argue that a social justice informed approach towards shaping a vision for science education in the post-pandemic era is of paramount importance and that failure to do so will only serve as a way of perpetuating existing inequalities.
\end{abstract}

Keywords: COVID-19 • PISA • science curriculum • science education • science $\mid$ environment $\mid$ health • science education research $\bullet$ neoliberalism $\bullet$ scientific literacy $\bullet$ trust 


\section{Introduction}

COVID-19; Coronavirus disease 2019; virus; SARS; pandemic; outbreak; herd immunity; the curve; flatten the curve; asymptomatic; underlying conditions; incubation period; physical distancing; social distancing; self-isolation; isolation; quarantine; lockdown; R-number; behavioural science; personal responsibility; social responsibility; political responsibility; Chinese hoax; fake news; vaccination; anti-vaccination; public engagement with science; distance education; online; virtual learning; video-conferencing; teleconferencing; personal; social; political; national; global. These terms have dominated the media over the past few months. New, technical and often unclear terms make up this glossary, which is currently used by politicians, scientists, journalists, educators, and the general public, to engage in discourses associated with the coronavirus disease 2019 (COVID-19). Some of the terms are used in an ambiguous and interchangeable manner, which serves as evidence of how unclear certain aspects of the pandemic still are. What it is clear, however, is that, as a global society, or as a group of interlinked societies, this has not been our finest hour.

Without doubt, many individuals have died who should still be alive and the emotional and financial impact on people's lives is incalculable. We have seen substantial failures of governance, decision making and leadership as well as inspiring and appalling examples of human behaviour. It has become obvious how much more complex than just a health issue the COVID-19 pandemic is. It touches upon all aspects of life and its impacts need to be understood across a wide range of disciplines.

For education in general, and science education in particular, the pandemic has created new realities and raised previously unthinkable challenges. Science and scientists find themselves in the spotlight as both potential saviours or as untrustworthy puppets in ways that would have been unthinkable a year ago. Yet science education and science educators are invisible. So, in this paper, we offer an initial reflection on what all this might mean for the science education community. We begin with a discussion on trust in science and we then raise a series of questions for the science education community.

\section{On Trust}

Education is fundamentally a process of trust and science education is no exception. Those of us who have taught in schools have spent countless hours communicating our interpretation of how the world works to hundreds and thousands of children. Implicit in this process is an assumption that, in general, young people believe what their teachers tell them. In reality, science teachers offer little by way of evidence to students to support all the facts that will later be tested throughout their education. Quite often, school science emphasizes the facts of science while the processes of science resemble a "black box". Students are rarely taught about the processes of scientific research even though it is these processes that might save millions of lives. What scientists do, what kinds of data they collect and how they analyze those data to form conclusions, remain a mystery for most young people.

Part of the problem is that science deals with things that can't be seen and ideas that are often incredibly sophisticated. Science in school is presented as a straight-forward, logical, empirical and reliable enterprise carried out by highly trained and trustworthy people. While the truth is that picture is some distance from reality, most students believe it sufficiently to make science teachers' jobs relatively straightforward. As a result, public trust in scientists is relatively high. For example, the Pew Research Center survey last year found that ' $35 \%$ of [US] Americans say they have a great deal of confidence in scientists, up 14 percentage points from 2016' (Funk et al., 2019). Another 51\% had 'a fair amount' of 
confidence in scientists. Hardly the most encouraging figures but much higher than 'the news media, business leaders and elected officials' (Funk et al., 2019).

Although research shows that the public has high trust and confidence in science and believes that science provides great benefits to the world, many people continue to deny the conclusions of science in areas such as evolution, climate change and vaccination. Why do people refuse to accept the scientific consensus on these topics despite their high confidence in science generally? Research has shown a link between political convictions and acceptance of climate change science (Motta et al., 2019) but why this is the case is still rather unclear (Druckman \& McGrath, 2019). At times like this, the call for science communication and public engagement with science becomes perhaps more important than ever before especially when ill-informed ideologies and anti-science discourses are on the rise.

Social media has allowed conspiracy theorists a platform for a wide range of improbable and impossible ideas:

... belief in the moon-hoax conspiracy has blossomed since 1969. Among 9/11 truthers, anti-vaxxers, chemtrailers, flat-

Earthers, Holocaust deniers and Sandy Hook conspiracists, the idea that the moon landings were faked isn't even a source of anger any more - it is just a given fact. (Godwin, 2019)

Whether anti-vaxxers will be equally resolute in rejecting the COVID-19 vaccine, whenever it is ready, remains to be seen. Most people, for obvious reasons, are relatively unaware of the science behind vaccines when they are given them as a child. When faced with a choice to take a vaccine that could save your life, your parents' lives and your children's lives, we suspect that most people will take it — and that will be a giant teachable moment that science education needs to exploit. But is the science education community ready to respond?

\section{Towards a Response to COVID-19 from the Science Education Community}

So far, the science education community has responded to the pandemic in three main ways. Firstly, conferences and seminars have been cancelled or moved online. Both cancellations and virtual versions of conferences and seminars come with certain limitations, including questions of whether or not they are equitable practices.

Secondly, some journals have put out calls for papers (as has JASTE). The usefulness of these is still to be justified with the kind of engagement and translation of theoretical ideas into practice. While the logic of responding in this way is obvious, perhaps it smacks too much of a "business as usual" approach?

Thirdly, much science education has gone online, whether it be at school level, college level or preservice teacher level. The question is whether school systems and universities in all countries were adequately equipped to do that, in terms of access to technology, the technological tools available, as well as the curriculum. A more crucial question is whether teachers and lecturers have the knowledge and skills needed to engage effectively in distance education and to implement pedagogies of care, and attend to students' affective needs during the pandemic. The plethora of terms used interchangeably, such as distance education, e-learning, blended learning, online learning, online teaching, remote teaching, virtual learning, serves to showcase at least a misunderstanding of the role of information and communication technology in higher education.

These three different practices provide an overview of the kinds of reactive practices of the community. What is missing, however, is a response to the pandemic which entails some inspiration, some leadership, some vision statement from organisations such as ASERA, EASE, ESERA, NARST and 
others. There are some obvious questions that the science education community might benefit from addressing.

\section{How well has the science curriculum prepared the world's public for COVID-19?}

Despite strongly advocating scientific literacy for decades, it is clear that far too many of the public are not, however you conceptualise the term, functionally scientifically literate. This science illiteracy is not limited to those with little education — it is also well-established in politicians, policy-makers and business leaders.

We believe that international tests, and PISA, in particular, have failed to provide adequate information about scientific literacy in any useful shape or form. Their influence has not led to the betterment of society; indeed, they have forced many school systems to adopt reductionist curricula and a narrow range of pedagogies. We believe that now is the time for all members of the science education community to withdraw from any involvement in PISA. More importantly, we believe that the science curriculum should be reoriented towards a science / environment|health perspective as advocated by Zeyer and Dillon (2019) and others.

2. How much science education should be online from now on? Are we learning from the current situation?

The current situation suggests that schools' prime role is to allow parents and carers to go to work in order to sustain an increasingly fragile economy. Imagine if we face another pandemic in a few years? Are we searching for innovative and sustainable solutions for science education and schooling? We need to be in a position to switch to an accessible, inclusive, equitable and engaging science education online with support for parents and carers quickly. At the moment we do not seem to be learning anything systematically about what works in terms of taking schools online.

3. Is science education research producing knowledge that protects society from catastrophic events?

Researchers need to use these moments to reflect on their contribution to both the current situation and to the future. Arguments that funders drive research only go so far. Is current science education research situated within contemporary socio-political realities? Do we really need another study that pre-service teachers don't know much about anything? Do we need yet more evidence that children's drawings of scientists reflect societal stereotypes? Effective research with a focus on social justice does not always need to be expensive and we suspect that in the light of the pandemic, funders will be taking a radical look at what gets funded in the future so we will need to adopt our practices accordingly and look elsewhere for support for research that addresses society's needs.

4. How should our working practices change to make science education more resilient, more useful and more transparent? 
Can we get by with fewer conferences? Would it hurt if annual conferences moved to biennial events? Do we need expensive venues in expensive cities? Could we reconceptualise conferences as practices of giving back to communities and supporting local economies instead of large corporations?

5. What are the ethics and politics of social distancing and how do they affect science education?

Unquestionably, the scientific basis for social distancing is robust; however, there are various ethical considerations that ought to be examine as well. In essence, social distancing is a process of boundary maintainance and which separates the population into 'us' and 'them'. Science and education, as cultural worlds, are no exception. One ethical consideration is whether social distancing is a Western, colonial construct more easily applicable in individualistic societies and completely ignoring the social premises of collectivistic societies and Indigenous communities. Another ethical consideration has to do with the risks of job loss and reduced income which affects the most disadvantaged and vulnerable populations. An intersectionality lens to examine the ethics and politics of social distancing, which are inevitably connected to science education, is crucial to informing equitable educational policies.

\section{What pedagogies might we need to turn to in the future?}

The pandemic has brought to the surface persisting structural inequalities that demand new ways of being in the world that centres on 'affect' instead of on 'success'. Researchers in education have called for an affective turn in education that places pedagogies of care and affect at the centre for several years now, in response to the fact that many countries, especially in the West have adopted neoliberal ideologies as the basis for reform in their educational systems. Neoliberalism is found within efforts for privatization and marketization of education, the globalization of a colonial curriculum, the rise of standardised testing, accountability, and competition - essentially, the creation of a capitalist school. What might a focus on affect or the adoption of culturally sustainable pedagogies and pedagogies of care in science education look like in practice? Such an affective turn requires engagement with questions such as: 'How do all children enter into positive relationships with science learning?', and, 'How could science education be made more affective and culturally relevant to become more equitable?'

7. What role should business and industry play in funding science education research and development?

Historically, educational research has been funded through goverments, a trend that has started to change in the last decade, at least in the West. We have witnessed greater interest from the private sector in educational research. Being forced to explore the potential of various technologies and digital tools for teaching and learning, might serve as an awakening to the possibilities of the private sector and industry in sponsoring educational research and forming of industry-university coalitions. If so, what role is envisioned for the business and industry to play in shaping educational reform? We are aware of the potential risks to researchers' freedom of expression here.

\section{Towards a Vision for Science Education in the Post-pandemic Era}


In thinking about a vision for science education in the post-pandemic era, we have raised a series of questions and offered initial thoughts about moving forward. We do not claim to know how the pandemic will shape science education or that we have solutions to pressing educational problems. This paper is simply an attempt to offer a departure point, an invitation for the science education community to engage with pressing issues in the field. The main question we pose for the community is the following: What can be done, and what can be done differently?

We envision that this paper will provide some guidance to the readers to re-think the complex systems and socio-political contexts within which people come to learn and practice science and to conceptualize these processes through a social justice lens. We argue that a social justice informed approach towards shaping a vision for science education in the post-pandemic era is of paramount importance and that failure to do so will only serve as a way of perpetuating existing inequalities.

We hope that this paper will provide the basis for conversations aligned with the inseparability of science education and social justice, especially in times like this, and move the field forward in directions that examine ways of using the crisis as an opportunity for a critical transformation.

\section{References}

Druckman, J.N., \& McGrath, M.C. (2019). The evidence for motivated reasoning in climate change preference formation. Nature Climate Change, 9(2), 111-119.

Godwin, R. (2019). One giant ... lie? Why so many people still think the moon landings were faked. The Guardian. Retrieved from: https://www.theguardian.com/science/2019/jul/10/one-giant-lie-whyso-many-people-still-think-the-moon-landings-were-faked

Funk, C., Hefferon, M., Kennedy, B., \& Johnson, C. (2019). Trust and mistrust in Americans' views of scientific experts. Retrieved from: https://www.pewresearch.org/science/2019/08/02/trust-andmistrust-in-americans-views-of-scientific-experts/

Motta, M., Chapman, D., Stecula, D., \& Haglin, K. (2019). An experimental examination of measurement disparities in public climate change beliefs. Climatic Change, 154(1-2), 37-47.

Zeyer, A., \& Dillon, J. (2019). Science| Environment | Health-the emergence of a new pedagogy of complex living systems. Disciplinary and Interdisciplinary Science Education Research, 1(1), 1-10. 